\title{
LA EVOLUCIÓN POLÍTICO-CONSTITUCIONAL DE CHILE
}

\author{
The political-constitutional evolution of Chile
}

\author{
Sergio Carrasco Delgado ${ }^{1}$ \\ Universidad de Concepción, Chile \\ scarrasc@udec.cl
}

RESUM EN: El presente trabajo analiza la evolución en sus aspectos principales del régimen político y de la situación electoral en Chile, ocurrida en los recientes treinta años.

Precedido por los antecedentes históricos pertinentes trata de lo sustancial en la Constitución Política de la República de Chile de 1980, en los triples aspectos de normas originales, reformadas y su aplicación. En especial se refiere al sistema de gobierno presidencial y sus matices, a los partidos políticos y a las tendencias que han modificado el desarrollo de la situación electoral chilena. Formulando, finalmente, las conclusiones que derivan del estudio efectuado.

PA LA BRAS CLAVE: Historia Constitucional de Chile. Derecho Constitucional. Régimen político. Sistema de gobierno presidencial. Reformas constitucionales. Sistema electoral. Sufragio. O pinión pública.

ABSTRACT: This paper analyse the evolution, in its main aspects, of the political regime and the electoral situation of Chile, happened in recent the thirty years. Proceded by the pertinent historical antecedents, it deals with the substancial thing in the 1980's Political Constitution of the Republic of Chile, in the triple aspects of original norms, reformed and their application. Specifically, it talks about the presidential government system and the shades, the political parties and the tendencies that have modified the development of the Chilean electoral situation. Finally, Formulating the conclusions the derive from the conducted study.

1 Decano y Profesor de Derecho Constitucional, Facultad de Derecho, Universidad de Concepción, Chile. Ponencia recibida el 30 de agosto de 2008 y aprobada el 22 de octubre de 2008. 
KEY WORDS: Constitutional History of Chile. Constitutional law. Political regime. Presidencial Government System. Constitutional reforms. Electoral System. Voting. Public Opinion.

\section{ANTECEDENTES}

En relación con las materias de análisis precisas de que trata esta ponencia, esto es, la evolución en sus aspectos principales del régimen político y de la situación electoral en Chile, correspondiente al período de los recientes treinta años, es necesario tener presente sucintamente, entre otros, los siguientes antecedentes:

1) Restaurando la tradición hispana en América, aun cuanto en expresiones constitucionales, ${ }^{2}$ desde los primeros textos pero muy precisamente desde la Constitución de la República Chilena, de 25 de mayo de $1833,{ }^{3}$ se consagró invariablemente -si bien con matices e interpretaciones- un régimen político que en lo sustancial situó al Presidente de la República como la figura central, por sobre el Congreso y las agrupaciones políticas posteriormente surgidas.

Tal régimen se aplicó sin cambio alguno prácticamente durante los primeros treinta años de la República Organizada, pero luego de un cambio político hacia 18731874 se modificaron las normas originales en términos de corresponder lo que siguió a "un régimen presidencial de partido", no obstante que en los gobiernos de 18811891 el "autoritarismo de hecho" presidió la realidad política. Posteriormente, luego de la grave crisis que derivó en la Guerra Civil de 1891, sin cambiar el texto de la Constitución los revolucionarios triunfantes del bando congresista establecieron -por medio de una interpretación de hecho- el denominado "seudo-parlamentarismo" (18911924), forma imperfecta que significó, en su aplicación efectiva, la anulación del poder presidencial y el predominio, sin contrapesos, del Congreso y más exactamente de las combinaciones formadas transitoriamente por los partidos políticos de la época.

2) Una nueva crisis político-constitucional, también con intervención militar, ${ }^{4}$ condujo a la dictación, previa aprobación por plebiscito, de la Constitución Política de la

2 A partir del incipiente Reglamento para el arreglo de la Autoridad Ejecutiva Provisoria de Chile, de 14 de agosto de 1811 y hasta la Constitución Política de la República de Chile, de 11 de septiembre de 1980, han existido, doce textos fundamentales, los Reglamentos de 1811, 1812 y 1814; las Constituciones de 1818 y 1822; los Reglamentos de 1823 y 1823 y las Constituciones de 1823, 1828, 1833, 1925 y 1980, las tres últimas con sus reformas.

3 El texto fundamental de más extensa vigencia: 1833-1925, aún cuando con diferentes interpretaciones en las siguientes tres etapas: 1833-1871; 1871-1891 y 1891-1924.

4 "La Revolución de los Tenientes", con su precedente inmediato y desencadenante denominado "Ruido de Sables", protesta en las galerías de las Cámaras cuando, no obstante otras numerosas urgencias económicas, se aprobaba el proyecto de ley sobre dieta parlamentaria y expresada, en cuanto a sus fundamentos en los "Postulados del 11 de septiembre de 1924". Pero la crisis político-constitucional tuvo causas remotas de mayor profundidad, que son, en general, las que se vinculan al curso mismo del período seudo-parlamentario. 
República de Chile de 18 de septiembre de 1925 (1925-1973 y luego parcialmente hasta 1980), uno de cuyos propósitos centrales fue el cambio del sistema de gobierno seudoparlamentario por el sistema presidencial, para lo cual se hizo elegible por votación directa al Presidente de la República, hasta entonces elegido por votación indirecta, decisión explicable por el distinto rol que el gobernante adquirió con motivo de la elección presidencial de 1920, en que "la popularidad" surgió como indispensable requisito de los futuros gobernantes. ${ }^{5} \mathrm{El}$ mandato se extendió a seis años de duración, sin reelección y, para el caso de no obtener alguno de los candidatos la mayoría absoluta de sufragios el Congreso Pleno debía elegir entre las dos primeras mayorías relativas.

En esta etapa de la evolución político constitucional no fue fácil concretar el restablecimiento del presidencialismo. Tanto por la inicialmente falta de vigencia efectiva de la Constitución, sólo obtenida después por el segundo gobierno del Presidente Arturo A lessandri después del año 1932, cuanto por los diversos hechos conspirativos con los que se pretendió interrumpir la constitucionalidad, ocurridos con mayor o menor intensidad durante todo el período de vigencia de la Carta y por la existencia de resabios parlamentaristas en importantes partidos políticos. ${ }^{6}$ En el hecho, casi todos los Presidentes de la República del período debieron sortear serios conflictos con el Congreso y las agrupaciones partidistas, llevando ello a declinar parte de sus atribuciones frente a los partidos políticos que los apoyaban o ante los más importantes grupos de presión existentes.

3) La crisis político constitucional, expresada también continuadamente en lo social, que culminó el 11 de septiembre de 1973,7 llevó al establecimiento de un gobierno de hecho que significó, en lo constitucional, la vigencia sólo parcial de la Carta de 1925 y la sucesiva dictación de decretos leyes, seguidos por la Constitución Política de la República de Chile de 11 de septiembre de 1980, con vigencia parcial hasta 1990 y luego con plenitud, agregándosele desde 1989 en adelante veinte reformas constitucionales.

El nuevo texto restableció el sistema presidencial, con un gobernante que duraría 8 años en su cargo,${ }^{8}$ elegible en votación directa con aplicación del sistema de segunda vuelta para el caso de existir mayoría absoluta en la primera elección. Al Presidente de la República se le dotó de mayores atribuciones, incluso en lo legislativo, en lo que se ha denominado un presidencialismo "vigorizado".

Las bases de la institucionalidad, fundadas en los valores de la dignidad de la persona humana, la libertad y la igualdad; la existencia de un pluralismo ideológico

\footnotetext{
Ver en GuerRa, José Guillermo, “La Constitución de 1925", p. 343: “En 1925, cuando se estudió la reforma constitucional... era necesario, además, poner término al régimen parlamentario devolviendo a la Nación su soberanía usurpada por los partidos con asiento en el Congreso. Convenía, entonces, modificar el sistema de elección presidencial en términos de darle un carácter más verdaderamente popular".

6 Principalmente en el Partido Radical, de especial importancia en la época.

7 Entre otras publicaciones sobre tal crisis, ver de Consejo General del Colegio de Abogados de Chile, "Antecedentes histórico-jurídicos, años 1972-1973", Santiago, 1980.

8 Término reducido, posteriormente, por las reformas constitucionales de 1994 y 2005.
} 
limitado; el mayor desarrollo de los derechos y deberes fundamentales; la participación militar en la sociedad política; el establecimiento de la regionalización; el reconocimiento del poder social y la no exclusividad del poder político y la consideración de medios exigentes de reforma que reforzaran la estabilidad constitucional, forman parte, además, de las finalidades principales del régimen de gobierno expresadas en el texto original de la Carta de $1980 .^{9}$

4) En cuanto a la situación electoral, la forma de elección indirecta del Presidente de la República se mantuvo sin variación en las diecinueve elecciones de este orden efectuadas hasta el año de 1920, incorporándose la forma de elección directa sólo desde 1925, con la primera de las dieciséis similares elecciones siguientes. Respecto del Congreso Nacional, hubo siempre diferencias en cuanto a la composición y funciones del Senado y las de la Cámara Diputados, pero aplicándose ya desde el período de la Constitución Política de 1925, para la elección de ambas cámaras uniformemente aun cuando con matices, el sistema electoral proporcional o de D'Hondt.

La participación electoral en el período 1925-1946 fue muy reducida, fluctuando entre los 302.142 y los 641.505 inscritos, con márgenes de abstención importantes, con un promedio superior al 20\%. Las cifras citadas variaron en el período 1952-1970, con cifra inicial de 1.005 .029 y final de 3.539.747 inscritos, siendo el promedio de abstención superior al $15 \%$. Si se considera la proporción del número de electores inscritos en relación a la población nacional, en 1925 era sólo el 7,42\% y en 1970 el $36 \%{ }^{10}$

Tal crecimiento se debió, por una parte, a un mayor acceso o interés a participar en la vida cívica; a la obligatoriedad de la inscripción en los registros electorales y del sufragio mismo; a la incorporación (1934 y 1949) del sufragio femenino, que inicialmente llegó al 30\% del registro total de electores y luego de veinticinco años al 50\% del mismo; la rebaja de la edad mínima para sufragar de los 21 a 18 años y, en menor proporción, a la ampliación del derecho a los analfabetos y no videntes (1970).

\section{SOBRE EL RÉGIMEN DE GOBIERNO EN LOS RECIENTES TREINTA AÑOS}

5) Tanto el texto mismo de la Constitución Política de la República de 1980 cuanto el régimen de gobierno por ella consagrado y su aplicación han experimentado, en el período de los recientes treinta años, importantes y frecuentes modificaciones. ${ }^{11}$

9 Sobre estos aspectos, ver de CARRASCo D., Sergio (2006), "Finalidades, aplicación y reforma de la Constitución Política de 1980. ¿Es una nueva Constitución", en XXXV Jornadas Chilenas de Derecho Público. El Derecho Público Chileno ante la globalización, Valparaíso, pp. 37 a 52.

10 En el año 1973 el número de electores inscritos fue de 4.509 .559 , correspondiente al $45,73 \%$ del número de habitantes.

11 Ver las siguientes veinte Leyes de reforma constitucional: a) Gobierno Presidente Augusto Pinochet U., $n^{\circ}$ 18.825, de 17 de agosto de 1989; b) Gobierno Presidente Patricio Aylwin A., $n^{0 s} 19.055$, de $1^{\circ}$ de abril de 1991; 19.097, de 12 de noviembre de 1991 y 19.295, de 4 de marzo de 1994; c) Gobierno 
No obstante que el establecimiento en el texto de la fundamentación de los valores y principios propios de la civilización cristiano occidental, que son la dignidad de la persona humana, la libertad y la igualdad; de la familia como núcleo fundamental de la sociedad; de la concreción del bien común y su promoción, del principio de subsidiariedad; del reconocimiento y amparo de los grupos intermedios y de la servicialidad del Estado ${ }^{12}$ y el amplio catálogo de los derechos fundamentales, salvo el respeto y protección a la vida pública, su amparo y protección, ${ }^{13}$ así como los deberes esenciales ${ }^{14}$ se han mantenido con escasos cambios y han permanecido como aporte normativo de la Constitución, ${ }^{15}$ no ha ocurrido lo mismo con la mayor parte de las materias contenidas en los demás capítulos de la Constitución Política. Ni, por consiguiente, con la aplicación de sus disposiciones.

6) A sí, y señalando -entre otras- las que se consideran de especial importancia, ya en 1989, se eliminó el artículo $8^{\circ}$ del texto, continente de lo dispuesto sobre el pluralismo ideológico limitado; han desaparecido o se han atenuado importantemente las disposiciones sobre intervención militar en la sociedad política chilena; igual ha ocurrido con el reconocimiento del poder social y la no exclusividad del poder político; se

Presidente Eduardo Frei R-T., nos 19.448, de 20 de febrero de 1996; 19.519, de 16 de septiembre de 1997; 19.526, de 17 de noviembre de 1997, 19.541, de 22 de diciembre de 1997, 19.597, de 14 de enero de 1999; 19.611, de 16 de junio de 1999; 19.634, de 2 de octubre de 1999 y 19.643, de 4 y 5 de noviembre de 1999; d) Gobierno Presidente Ricardo Lagos E., nos 19.672, de 28 de abril de 2000; 19.671, de 29 de abril de 2000; 19.742, de 25 de agosto de 2001; 19.876, de 22 de mayo de 2003 y 20.050, de 26 de agosto de 2005: y e) Gobierno Presidenta Michelle Bachelet J., nos 20.162, de 16 de febrero de 2007, 29.193, de 30 de julio de 2007 y 20.245, de 9 de enero de 2008.

12 Constitución Política de la República, Capítulo I, artículo $1^{\circ}$.

13 La acción constitucional de protección, establecida en el artículo 20 de la Carta vigente, ha concurrido decisivamente en favor del resguardo de la mayor parte de los derechos fundamentales. Pese a algunas limitaciones en su interposición y trámites, que derivan de disposiciones contenidas en los autos acordados que se han dictado, y que en parte se han corregido después, es indudable que se ha convertido en el más eficiente medio de preservar los derechos. Entre otras observaciones que pueden formularse se encuentra el hecho de acogerse en importante proporción por la Corte Suprema los recursos llegados en apelación y, por otra, la mayoritaria acogida en virtud de estimarse transgredido el derecho de propiedad, al cual se le ha dado gran extensión. Diversas acciones se han acogido respecto de personas públicas, tales como la Dirección del Trabajo, por atribuirse funciones interpretativas de leyes y contratos, hospitales, establecimientos educacionales o las Municipalidades, recurridas por vecinos e incluso por sus funcionarios, así como deducidas contra particulares, clínicas, Isapres, etc. De importancia han sido, asimismo, las acciones acogidas y que han invocado el derecho a la vida e integridad física y síquica de las personas, garantizado en el artículo $19 \mathrm{n}^{\circ} 1$ de la Constitución. Por otra parte, la ley de reforma $n^{\circ} 20.050$, de 2005, amplió la procedencia de la acción de protección en cuanto al derecho a vivir en un medio ambiente libre de contaminación.

14 Ver en Constitución Política de la República de 1980, Capítulos I y III, respectivamente. Tal permanencia también ha ocurrido con la forma del Estado, la soberanía nacional y sus límites, la supremacía constitucional y la investidura regular de sus órganos. También se ha mantenido invariable el texto del Capítulo XIII, sobre Banco Central.

15 De importancia son las agregaciones del deber del Estado de respetar y promover los derechos fundamentales garantizados por la Constitución así como por los tratados internacionales ratificados por Chile y que se encuentren vigentes y de la restricción de los efectos correspondientes a los estados de excepción, ambas contenidos en la ley de reforma constitucional $n^{\circ} 18.825$, del año 1989, ya citada. 
redujo la duración del término del período presidencial ${ }^{16} \mathrm{y}$, finalmente, después de un extenso debate público así como de dos experiencias periódicas, se suprimió la parte de composición no electiva del Senado.

7) En cuanto al cambio de las disposiciones sobre participación militar en el régimen político, al equipararse, en el Consejo de Seguridad Nacional, el número de integrantes de procedencia civil con el de procedencia militar y variar sus funciones, sustituyéndose la de "representar" con la de "hacer presente", se inició el proceso conducente a hacer puramente nominal uno de los propósitos de la Carta de 1980, y que culminó con disponerse, en la reforma de 2005, que corresponde a los órganos del Estado garantizar el orden institucional de la República, ${ }^{17}$ que la función básica del Consejo de Seguridad Nacional es solamente asesora, que no adoptará acuerdos sino para dictar su reglamento, que se varió su integración quedando con mayoría de procedencia civil y que se le privó de todas sus atribuciones originales. ${ }^{18}$ Agregándose, en la reforma concretada, el término de la inamovilidad de los Comandantes en Jefe de las Fuerzas A rmadas y del General Director de Carabineros, pudiendo el Presidente de la República, con sólo un informe previo a la Cámara de Diputados y al Senado, llamarlos a retiro. ${ }^{19}$

Pese a que las normas constitucionales originales en esta materia fueron permanentemente impugnadas, en su conjunto, durante el período de plena vigencia de la Constitución de 1980, en su efectiva aplicación, se apreció una tendencia a la propia disminución del rol militar y a la vuelta al desempeño predominantemente presidencial. Así, si se estimó que la posible actividad de intervención militar en los asuntos políticos que se estimaba existiría a través del Consejo de Seguridad Nacional, en los hechos se dio una aplicación absolutamente distinta; sus sesiones fueron pocas y escasas las oportunidades en que se trataron materias políticas. ${ }^{20}$ Por otra parte, respecto de la norma que hacía garantes de la institucionalidad a las Fuerzas Armadas “... los propios uniformados siempre manifestaron su decisión de no recurrir a esa claúsula, por lo que paulatinamente se convirtió en letra muerta". ${ }^{21}$

8) Otro de los elementos de especial importancia considerado en el texto original de la Constitución Política, como se ha señalado, y posteriormente sustituido, fue el establecimiento de una separación entre el "poder social" y el "poder político". Expresado el primero con extensión en el tema de las inhabilidades parlamentarias y muy precisamente en los órganos de participación llamados “Consejos Regionales de Desarrollo", asesores del Intendente Regional y que designaban, salvo excepciones, a los

\footnotetext{
Sobre lo cual se hará referencia en el párrafo 14 de este trabajo.

Constitución Política de la República, Capítulo I, artículo $6^{\circ}$ inciso $1^{\circ}$.

Constitución Política de la República. Capítulo XII, artículos 106 a 107.

Constitución Política de la República, Capítulo XI, artículo 104.

20 En un período de 21 años el Consejo de Seguridad Nacional se reunió en 23 oportunidades y de 27 temas tratados sólo 4 pueden considerarse estrictamente políticos.

${ }_{21}$ CEA E., José Luis, entrevista en diario "El Sur", Concepción, de 22 de junio de 2003.
} 
Alcaldes, teniendo sí el Intendente derecho a vetar la terna que se le propusiera y los "Consejos de Desarrollo Comunales", que formaban la terna respectiva, órganos que tenían por finalidad evitar la influencia político partidista en tales niveles de gobierno.

Respecto de lo anterior, la reforma constitucional, de 1991, sobre establecimiento de Consejos Regionales y elección popular de alcaldes y concejales, estableció, en lo sustancial, que en cada M unicipalidad habría un Concejo, integrado por concejales elegidos por sufragio universal en conformidad a la ley orgánica constitucional. También las normas restrictivas en materia de inhabilidades, incompatibilidades y causales de cesación de los parlamentarios también fueron modificadas sustancialmente. ${ }^{22}$

9) Por lo que dice relación al procedimiento de reforma constitucional, que contuvo inicialmente elementos de especial rigidez, similares a los considerados originalmente en la Constitución Política de 1833, entre los años 1989 y 2005 fue modificado en tres ocasiones, ${ }^{23}$ en términos de hacer preferentemente flexible el mecanismo de reforma. ${ }^{24} \mathrm{No}$ obstante lo cual cabe consignar que, como ha sido la constante histórica chilena, la rigidez del mecanismo inicial no impidió que, frecuentemente, como ya se ha señalado, se le incorporaran numerosas modificaciones.

10) De especial importancia han sido las modificaciones correspondientes a composición del Senado y más precisamente la que suprimió la institución de los senadores incorporados, designados o institucionales. ${ }^{25}$ Su establecimiento tiene antecedentes de antiguo en la evolución constitucional chilena. Así principalmente lo propiciaron el constituyente M ariano Egaña Fabres en el Voto Particular formulado en la etapa final de elaboración de la Constitución Política de 1833; el Presidente de la República Arturo Alessandri Palma en la subcomisión de reforma donde se elaboró la Constitución de 1925; el Presidente Carlos Ibáñez del Campo en el proyecto de reforma constitucional de 1955 y el Presidente Jorge A lessandri Rodríguez en el proyecto de reforma constitucional de 1964 así como en el Consejo de Estado al elaborarse la Carta de 1980.

La institución de integración mixta del Senado, sólo encontró acogida en la última oportunidad señalada y así se mantuvo por dieciséis años. La crítica sustancial de ser estimada un enclave autoritario, que alteraba la generación por votación popular de sus integrantes, fue atenuándose ante el hecho de que la primera generación de sus miembros, si bien cercanos en sus nombramientos al gobierno militar, habitualmente actuaron como factor facilitador de muchas decisiones y también porque la segunda generación de sus miembros fue más cercana a los gobiernos de la Concertación de

22 Constitución Política de la República. Capítulo XIV, artículos 111 a 116, 118 a 199, 122 a 126. Capítulo V, artículos 57 a 61.

23 Por las leyes de reforma $n^{\circ s} 18.825$, de 1989; 19.671, de 2000; 19.526, de 1997 y 20.050, de 26 de agosto de 2005.

24 Constitución Política de la República. Capítulo XV, artículos 127 a 129.

25 Ver las leyes de reforma nos 18.825 , de 1989 y 20.050, de 2005. Constitución Política de la República, Capítulo V, artículos 49 y 50 , 
Partidos por la Democracia, incluso algunos de los senadores designados o institucionales de la segunda etapa representaron en su ejercicio a partidos políticos. En definitiva, sin mayores discrepancias y a partir de diferentes motivaciones, la institución se suprimió totalmente, sin que variara el número de senadores elegidos.

11) A demás de las modificaciones precedentemente tratadas, fue también un cambio de importancia el contenido en la ley de reforma de 1997, relativo a la designación de los miembros de la Corte Suprema, aumentando su número y haciendo participar en el nombramiento a los tres poderes del Estado, considerando la formación de una quina por la Corte Suprema, el nombramiento y proposición, por el Presidente de la República y el acuerdo del Senado por los dos tercios de sus miembros en ejercicio. Disponiéndose, también, que cinco de sus integrantes sean abogados extraños a la administración de justicia y derogando la inamovilidad en caso de edad de los magistrados de los tribunales de justicia, quienes pasaron a cesar en sus cargos al cumplir setenta y cinco años de edad, ${ }^{26}$ sin perjuicio de otros motivos y con la sola excepción del presidente de la Corte Suprema. ${ }^{27}$

Esta nueva forma de designación de los integrantes del máximo tribunal de justicia no ha estado exenta de dificultades y críticas. Surgidas, principalmente, del grado de politización que la decisión ha ido adquiriendo, motivando en algunas oportunidades el rechazo de la propuesta presidencial ${ }^{28} \mathrm{y}$, en todo caso, una suerte de "cuoteo", precedido con consultas al propuesto sobre sus criterios judiciales, lo que no sería consecuente con la base constitucional de independencia de los jueces.

12) Por otra parte, reforma constitucional de gran amplitud y efectividad ha sido la correspondiente al Tribunal Constitucional. ${ }^{29}$ M uy recientemente, en el año 2005, se varió su composición, aumentando a diez el número de sus miembros y estableciendo la participación, por separado, de los órganos ejecutivo, legislativo y judicial en la generación de los integrantes del tribunal, nombrando tales órganos a tres, cuatro y tres miembros, respectivamente.

A demás, y muy sustancialmente, se aumentaron sus atribuciones, correspondiéndole, en síntesis y con diversas precisiones ${ }^{30}$ el control previo de constitucionalidad de las leyes interpretativas de la Constitución, de las leyes orgánicas y de las normas de los tratados que versen sobre materias de éstas; las cuestiones de constitucionalidad de los autos acordados, de los proyectos de reformas constitucionales, de ley y de los tratados; de la convocatoria a plebiscito; la resolución sobre inaplicabilidad e inconstituciona-

26 Leyes de reforma constitucional nos 18.825, de $1989 ; 19.519$, de $1997 ; 19.541$, de $1997 ; 19.597$, de 1999 y 20.050, de 2005. Constitución Política de la República, Capítulo VI, artículos 76 a 78, 80 a 82. Quien continuaría en su cargo hasta el término de su período.

28 Habitualmente superada por una propuesta posterior con el mismo candidato.

29 Creado, con otra integración y atribuciones en la ley de reforma $n^{\circ} 17.284$, de 1970 y contemplado, asimismo, en el texto original de la Constitución Política de 1980. Ver leyes de reforma 19.541, de 1997 y 20.050, de 2005. Constitución Política de la República, Capítulo VIII, artículos 92 a 94.

30 Texto íntegro, en Constitución Política de la República, Capítulo VIII, artículo 93. 
lidad de preceptos legales; los reclamos sobre promulgación de la ley; la resolución sobre constitucionalidad de decretos o resoluciones del Presidente de la República representados de inconstitucionalidad la Contraloría; la declaración de inconstitucionalidad de organizaciones, movimientos o partidos políticos y la responsabilidad de personas participantes en los hechos que motiven la declaración; el informe al Senado en el caso de inhabilidad del Presidente de la República; la resolución de contiendas de competencia que no correspondan al Senado; lo correspondiente a inhabilidades de los M inistros de Estado; el pronunciamiento sobre inhabilidades, incompatibilidades y causales de cesación de los parlamentarios; la calificación de la inhabilidad y pronunciamiento sobre la renuncia de parlamentarios y la resolución sobre la constitucionalidad de los decretos supremos cuando se refieran a materias propias de ley.

Tan extensa competencia, cuyo ejercicio posterior ha sido objeto de polémicas e incluso de críticas por haberla así contemplado, ha permitido al Tribunal Constitucional dictar un conjunto numeroso de fallos con consecuencias políticas de trascendencia. ${ }^{31}$

13) La explicación de éstos y muchos otros cambios a la Constitución Política puede encontrarse principalmente en la variación experimentada por las realidades políticas en los recientes veinte años; en la escasa tradición en el régimen constitucional chileno de varias de las instituciones modificadas; en el predominio electoral de la combinación política de "Concertación de Partidos por la Democracia" y en la acogida o reconocimiento, dentro y fuera del Congreso por los partidos de oposición, organizados con diversas denominaciones, la más actual "Alianza por Chile", de la mayor parte del contenido de las modificaciones efectuadas. ${ }^{32}$

De hecho, la ley $n^{\circ} 20.050$, del año 2005 , que junto a la $n^{\circ} 18.825$ del año 1989 , son las más importantes en el proceso de modificación de la Constitución, fue el resultado de la combinación de dos proyectos de reforma, procedentes, respectivamente, de cada una de las grandes combinaciones políticas actuales. ${ }^{33}$

31 En particular, y entre muchos, los vinculados a derechos fundamentales, justicia tributaria, desafuero e inhabilidad de parlamentarios.

32 Diferente explicación nos parece es la que cabe formular respecto de las mayores atribuciones que se entregaron al Tribunal Constitucional, en que primó la razón de fortalecer el control de la constitucionalidad, tendencia surgida más bien en el debate en el Congreso y como resultado de las sugerencias académicas.

33 Sobre el tema, ver Varios Autores (Coordinador: Francisco Zúñiga) (2005), Reforma Constitucional, Santiago, octubre. Las materias sustanciales consideradas en esta reforma fueron 105.

Las realidades y cambios políticos, así como la aplicación de la Constitución Política de 1980 dejaron atrás la discusión sobre la legitimidad del texto, materia sobre la cual hubo sí extensa bibliografía y discusión. Al efectuarse la reforma de 2005 y dictarse el texto refundido, coordinado y sistematizado, no prosperó el cambio de denominación, por el sugerido de Constitución Política del 2005. No obstante que, en insinuación en tal sentido, el Decreto Supremo $n^{\circ} 100$, del Ministerio Secretaría General de la Presidencia, de 22 de septiembre de 2005, suprimió la invocación tradicional del "nombre de Dios Todopoderoso", que se encontraba en los textos fundamentales desde 1833. Al respecto, ver artículo "Sobre el Decreto Promulgatorio de la Constitución de Chile "En nombre de Dios Todopoderoso", en Actas XXXIV Jornadas de Derecho Público, Facultad de Derecho de la Pontificia Universidad Católica de Chile, Santiago, 2005, pp. 349 a 359. 
Algunos de los cambios a la Constitución se concretaron ya con la primera ley de reforma, de 1989, ${ }^{34}$ pero otros fueron resultado, no obstante algunos rechazos originales, de partes de una extensa y a veces interrumpida negociación política en que -en ocasiones- la propia oposición experimentó diferencias importantes de criterios.

14) Todo el cambio constitucional precedentemente esbozado, cualquiera hayan sido sus finalidades específicas y generales, entre las cuales se encuentra de modo principal la de democratización del texto fundamental, ${ }^{35}$ puede estimarse que, en lo sustancial, no ha variado el sistema presidencial de gobierno.

Pero debe también concluirse que, en su aplicación, se le ha quitado paulatinamente al sistema presidencial el peso que originalmente se contempló en la Constitución.

Esto ha sido y es así, principalmente porque con posterioridad al año 1989 los partidos políticos representados en el Congreso recuperaron en el hecho el rol de importancia electoral, y por tanto política, tenida durante el período histórico anterior al del gobierno militar.

Debe agregarse que las reformas constitucionales que redujeron importantemente la duración del período presidencial, de 8 años a 6 y luego a 4 años y siempre sin reelección ${ }^{36}$ indican claramente la disposición dirigida a disminuir el rol efectivo del Presidente de la República. Si bien ya se han formulado iniciativas, no concretadas, de restituir al gobernante un período algo mayor.

La suma de ambas circunstancias, sistema presidencial de gobierno, con duración reducida, e importancia electoral de los partidos políticos, contribuye a explicar que el secular dilema de la relación Presidente-Congreso-Partidos Políticos ${ }^{37}$ continúe existiendo, sólo que con otras formas, asociadas contemporáneamente a los denominados "equilibrios políticos".

34 La negociación política que la originó, y que se prolongó entre octubre de 1988 y junio de 1989, a partir de la iniciativa de la directiva del partido Renovación Nacional, se desarrolló con un inicial rechazo y posterior disposición favorable del gobierno militar a lo que se agregaron proposiciones de diálogo de la entonces oposición.

Sobre la misma, en la obra precedentemente citada, ver de Cum PLIDo C., Francisco, Reforma constitucional y régimen político, p. 114 : “La estrategia de la Concertación consistió, entonces, en lograr introducir el mayor número de reformas que debilitaran el objetivo tenido en cuenta por los autores de la Constitución".

35 No obstante esta finalidad general de democratización, en la reforma constitucional por ley $n^{\circ} 20.050$, del año 2005, se contiene una norma sustancialmente antidemocrática, sobre reemplazo de los parlamentarios, que es la contenida en el artículo 51 inciso $3^{\circ}$ de la Constitución: "Las vacantes de diputados y las de senadores se proveerán con el ciudadano que señale el partido político al que pertenecía el parlamentario que produjo la vacante al momento de ser elegido", disposición que ya se ha cumplido. A la vez, se mantiene, en el inciso final del mismo artículo citado, la norma ya anteriormente existente de que "En ningún caso procederán elecciones complementarias".

36 Leyes de reforma nos 19.295, de 1994 y 20.050, de 2005. La primera se promulgó ya elegido el Presidente por el período que se inició en marzo de 1994.

37 Ver Bravo L., Bernardino, Régimen de Gobierno y partidos políticos en Chile. 1924-1973, pp. 85 a 132. 
En efecto, aun cuando se ha mantenido la regla constitucional de que el Presidente de la República designe libremente, "a su voluntad", a los ministros de Estado y altos funcionarios, ${ }^{38}$ es un hecho que, con mayor o menor intensidad, los presidentes del período posterior a 1989, como elemento indispensable para contar con apoyo en el Congreso, han debido efectuar tales nombramientos considerando en aquéllos la representación proporcional de integrantes de los partidos políticos que forman parte de la combinación política gobernante, con exclusión de cualquiera otros que estimara efectuar. A la vez, casi la totalidad de los cambios ministeriales, en aumento los más recientes diez años, han obedecido a esta razón.

15) Así, si se considera -en un período de treinta años, que va de 1978 a 2008- el número de personas que han desempeñado los cargos de Ministro de Estado en aquellas carteras de mayor importancia política, o más sensibles a las principales materias públicas, o sea, cuál ha sido la estabilidad ministerial, se evidencia la siguiente situación:

\begin{tabular}{|l|c|c|c|}
\hline Ministerio & 1978-1989 & 1990-1997 & 1998-2008 \\
\hline Interior & 6 & 3 & 6 \\
Defensa & 3 & 3 & 7 \\
Secr. Gral. Gobierno & 11 & 3 & 8 \\
Secr. Gral. Presidencia & - & 3 & 8 \\
Educación & 7 & 4 & 7 \\
Relaciones Exteriores & 6 & 3 & 4 \\
Hacienda & 7 & 2 & 3 \\
\hline Totales & 40 & 21 & 43 \\
\hline
\end{tabular}

Ingresando con mayor detalle al tema, se aprecia en los últimos dieciocho años una muy precisa estabilidad en el ejercicio de quienes ejercen el ministerio de Hacienda, en que incluso un ministro lo fue por seis años.

Muy distinto es el caso de los Ministerios Secretaría General de la Presidencia y Secretaría General de Gobierno, que se asocian a la relación entre el Gobierno y el

38 Constitución Política de la República, Artículo 32. “Son atribuciones especiales del Presidente de la República... $7^{\circ}$ Nombrar y remover a su voluntad a los ministros de Estado, subsecretarios, intendentes y gobernadores". 
Congreso y a la vinculación con la opinión pública, respectivamente. Los frecuentes cambios ministeriales en las dos carteras es posible asociarlos a serias dificultades políticas. De forma similar, la inestabilidad en los titulares en las carteras de Interior, Educación y Defensa pueden vincularse a variaciones o crisis políticas.

Por lo tanto, el estudio de las cifras precedentemente expuestas indican que la aceptable estabilidad política mantenida entre los años 1989 y 1997 ha cedido a una situación de relativa inestabilidad, lo que indica una difícil ejecución de las políticas públicas y la existencia de dificultades que afectan la forma de gobierno presidencial.

16) En otros aspectos, y haciendo referencia a algunas modificaciones que se habrían incorporado para robustecer la actividad del Congreso frente al Presidente de la República, puede estimarse que -salvo parcialmente- carecen de real importancia política y jurídica práctica, salvo su recepción por la opinión pública. Así ocurre con la ampliación de la norma sobre atribuciones exclusivas de la Cámara de Diputados en cuanto fiscalizar los actos del Gobierno, más precisamente con la posibilidad del denominado como el derecho a interpelar a los ministros y también con el funcionamiento $y$ funciones de las comisiones especiales investigadoras. ${ }^{39}$

Respecto de la acusación constitucional o política, ${ }^{40}$ comparativa con la experiencia constitucional anterior, su presentación ha sido escasa ${ }^{41}$ y sin que se afectara, por esta vía, el sistema político presidencial. Excepción hace a ello la acusación deducida y acogida, en 2008, en contra de la titular del M inisterio de Educación.

17) Complementariamente a lo expuesto, debe consignarse que el gran tema de las relaciones Gobierno-Congreso-Partidos Políticos continúa vinculándose, asimismo, con las concepciones e intereses de las distintas fuerzas políticas y también, si bien muy ocasionalmente, con una eventual sustitución del sistema presidencial de gobierno por uno semipresidencial, cuestión ya planteada con alguna intensidad hacia 1990.

En tal época, con motivo de la iniciativa dentro del gobierno del Presidente Patricio Aylwin de formular proyectos de reformas constitucionales, y no obstante plantearse ocasionalmente en los círculos políticos, “... A la Comisión se le sugirió no incorporar en sus proposiciones el cambio del régimen presidencialista de la Constitución de 1980 por un régimen semipresidencial, por cuanto se estimaba que todavía no se había producido una decantación en esta materia ni logrado un consenso sobre la conveniencia de plantear un cambio del régimen político". ${ }^{42}$

\footnotetext{
39 Ver Constitución Política de la República, artículo 54, 1) letras a), b) y c). Observando desde un punto de vista general, la mayor incidencia de estos mecanismos, salvo excepciones, ha estado vinculado a la exposición pública de los temas tratados.

40 Ver Constitución Política de la República, artículo 54, 2.

41 Entre los años 1991 y 2003 se registran sólo trece acusaciones constitucionales, y de éstas únicamente cinco se interpusieron en contra de Ministros de Estado, siendo todas rechazadas en la Cámara de Diputados.

42 Ver en Andrade G., Carlos, “Proyectos de reformas constitucionales en tramitación y estudio y comen-
} 
18) A simismo, se vincula el dilema Presidente-Congreso-Partidos Políticos con la percepción que sobre el tema tiene la opinión pública y con el grado de adhesión o rechazo al rol de las principales instituciones y actores políticos.

Así, una muy reciente encuesta sobre "Sondeo Latinoamericano", efectuado en Chile por el Instituto de Ciencia Política de la Universidad Católica de Chile, ${ }^{43}$ indica como resultados, en la escala de 1 a 7, para los alcaldes una calificación de 4,68; para la Presidente de la República la de 4,5 , con un $34,6 \%$ que señala efectúa un trabajo muy bueno o bueno, y para los diputad os una calificación de 3,19, llegando los niveles de confianza en los partidos políticos a un 3,46 , con $75,4 \%$ de encuestados que declaran no simpatizar con algún partido y $20,6 \%$ que sí.

Aun cuando tales resultados no guardan directa relación con la solidez institucional, constituyen sí un factor de interés a considerar en el gran tema contemporáneo de la satisfacción o malestar ciudadano, el cual obviamente ha influido siempre en los cambios políticos.

\section{SOBRE LA SITUACIÓN ELECTORAL CHILENA EN LOS RECIENTES TREINTA AÑOS}

19) En materia electoral es también de especial interés destacar que el proceso de la reorganización de los partidos políticos de y su incorporación con intensidad a la vida cívica después de los resultados del plebiscito de 5 de octubre de $1988^{44}$ debe ser analizado en relación al crecimiento del cuerpo electoral y a las opiniones generales de la población.

20) Durante el período que se inicia con la referida actividad, han existido, principalmente, dos grandes combinaciones políticas, que agruparon a diversos partidos, los cuales concluyeron finalmente en los seis de mayor consistencia electoral.

La inicial "Alianza Democrática", constituida por ocho colectividades o fracciones, al formarse como "Concertación de Partidos por la Democracia" agrupó en sus comienzos a diecisiete entidades. ${ }^{45} \mathrm{Si}$ bien las que llegaron a tener importancia fue-

tarios de las proposiciones del Ministerio Secretaría General de la Presidencia de la República", en Universidad Diego Portales, Escuela de Derecho, Cuadernos de A nálisis Jurídico, 15, p. 78.

Muy recientemente, el ex Presidente Patricio Aylwin A. ha declarado, en la sede del Congreso, que su visión, luego de su experiencia, es cada vez más "presidencialista". Ver en diario "El Mercurio", Santiago, de 27 de agosto de 2008.

43 Ver resumen en diario "El Mercurio", Santiago, de 24 de agosto de 2008.

44 Plebiscito que por un $55 \%$ de sufragios (alternativa No) rechazó la proposición que permitía la renovación del mandato presidencial del general Augusto Pinochet U., (alternativa Sí), que obtuvo el $43 \%$ de los sufragios. Lo que abrió paso, posteriormente, como se ha referido a un acuerdo político GobiernoOposición traducido en la ley de reforma constitucional $n^{\circ} 18.825$, de 1989.

45 Entre éstas, cinco fracciones socialistas, lo que las volvía a sus orígenes históricos, caracterizados por su fragmentación. 
ron los partidos Demócrata-Cristiano, Por la Democracia, Socialista y Radical SocialDemócrata. ${ }^{46}$

Por otra parte, los partidos Unión Demócrata Independiente y Renovación Nacional se agruparon en el Pacto "Democracia y Progreso", después denominado sucesivamente "Participación y Progreso", "Unión por el Progreso", "Unión por Chile" y finalmente "Alianza por Chile", que es el actual. ${ }^{47}$

No obstante las diferencias de orden político, en el período posterior a 1990 ha existido un general acercamiento entre las colectividades de este orden, incluso en términos de lo actualmente mencionado como "transversalidad", dando origen a políticas más o menos cíclicas de consensos.

El tema es muy extenso, porque también debe comprender el análisis del rol que en un estado democrático corresponde a quienes participan de un gobierno y a quienes deben ser oposición.

Al respecto, con motivo de la cercanía del "Bicentenario" 48 se ha producido, convocada por el Arzobispo de la A rquidiócesis de Santiago, una reunión en que participaron los presidentes de los ocho partidos políticos en actividad, emitiéndose una declaración-compromiso en cuanto afirmar "... la necesidad de promover una verdadera amistad cívica". ${ }^{49}$

También han tenido participación otros partidos políticos, pero de efímera trayectoria o significación. Hacen excepción el Partido Humanista y especialmente el Partido Comunista, que han participando en todas las elecciones efectuadas, ${ }^{50}$ si bien con resultados menores y prácticamente sin obtener representación parlamentaria, según se señalará.

46 Al primero pertenecen los ex Presidentes Patricio Aylwin A y Eduardo Frei R-T. Y al Partido Socialista el ex Presidente Ricardo Lagos E. (también al PPD) y la Presidenta Michelle Bachelet J.

47 Denominaciones empleadas desde los años 1989, 1992, 1993, 1997 y 2000, respectivamente. Los candidatos presidenciales del Pacto fueron Hernán Buchi B., Arturo Alessandri B., Joaquín Lavín I. y Sebastián Piñera E. (en segunda vuelta).

48 Corresponde a la conmemoración de los 200 años de la constitución en Santiago de la Primera Junta Nacional de Gobierno, el 18 de septiembre de 1810. La Independencia Nacional sólo se declaró en Concepción el $1^{\circ}$ de enero de 1818.

49 "Compromiso de los partidos por el Bicentenario", de 25 de julio de 2008, suscrita por los presidentes de los partidos Comunista de Chile, Demócrata-Cristiano, Humanista, por la Democracia, Radical SocialDemócrata, Renovación Nacional, Socialista de Chile y Unión Demócrata Independiente. Texto publicado en diario "El Mercurio", de 27 de julio de 2008.

50 En las elecciones presidenciales de los años 1993, 1999 y 2005, el Partido Humanista presentó como candidatos presidenciales a Cristián Reitze C. y Tomás Hirsch G., en dos oportunidades, obteniendo el $1,12 \%, 0,50 \%$ y 5,40 \%, respectivamente. El Partido Comunista tuvo como candidatos presidenciales a Eugenio Pizarro P. y Gladys Marín M. obteniendo el 4,43\% y 3,10\%, respectivamente; en el año 2005 apoyó al candidato Tomás Hirsch. 
21) Las dos grandes combinaciones políticas mencionadas han tenido estabilidad, en parte por la concurrencia de factores generales y específicos de unidad, ${ }^{51}$ pero también por la existencia del sistema electoral denominado binominal, cuya finalidad central fue y es la de evitar el multipartidismo y la dispersión electoral..$^{52}$

Respecto del sistema binominal, ha recibido una constante crítica procedente de los partidos políticos minoritarios y en particular del Partido Comunista, así como también del pacto de la Concertación de Partidos por la Democracia y de sus gobiernos. Incluso se han presentado iniciativas de reforma dirigidos a evitar la denominada exclusión, pero no se han concretado, principalmente por la negativa de los partidos opositores. La más reciente, que tampoco fructificó, consideraba -en líneas generales- la asignación de un número de elegidos, según la votación global, a los partidos minoritarios.

Tal falta de cambio del sistema ha llevado, tratándose de las próximas elecciones municipales, a que se haya llegado a acuerdos entre el pacto indicado y el Partido Comunista de "omitirse" en algunas comunas, para que así se tenga por este partido la posibilidad de elegir un número mayor de alcaldes, apoyando éste por su parte a la Concertación en otras comunas en que el resultado sea incierto o dudosamente favorable para esta combinación política.

Los criterios favorables a la mantención del sistema binominal se han apoyado, principalmente, en las ventajas de haber aquél contribuido a la estabilidad política y a una necesaria unificación de las tendencias mayoritarias. Además de sostenerse que, aun cuando los distritos o circunscripciones eligen cada uno dos parlamentarios, la determinación de los elegidos resulta de la aplicación de la regla de la proporcionalidad; por lo cual a los partidos minoritarios, mientras mantengan esa condición, no les correspondería cargos según sus resultados. M enos frecuente es la mención, aunque existe, de una razón que es de conveniencia mutua, cual es la elección de un número mayor de parlamentarios por las dos grandes combinaciones políticas, gracias a la existencia del sistema binominal.

22) Algunas cifras, siguientes, correspondientes a elecciones de diputados, contribuyen al análisis del tema. ${ }^{53}$

51 Un tema histórico político de interés y recurrente es el de la unidad entre partidos políticos o tendencias distintas. Habitualmente se generan en la coincidencia en la oposición conjunta hacia gobernantes o tendencias y, también habitualmente, desaparecido tal factor tienden a dividirse, recuperando su identidad. Así ocurrió, en Chile, principalmente con los gobernantes Bernardo O'Higgins R. (1818-1823), Manuel Montt M. (1851-1861), José Manuel Balmaceda F. (1886-1891) y Carlos Ibáñez del C. (1927-1931).

52 Además de las disposiciones constitucionales pertinentes, las principales leyes electorales, con sus modificaciones, han sido las orgánicas constitucionales $n^{\circ s} 18.460$, de 15 de noviembre de 1985 , sobre Tribunal Calificador de Elecciones; 18.556, de 1 de octubre de 1986, sobre Sistema de Inscripciones Electorales y Servicio Electoral, y 18.700, de 6 de mayo de 1988, sobre Votaciones Populares y Escrutinios, y la ley $n^{\circ} 19.884$, de 5 de agosto de 2003, sobre Transparencia, Límite y Control del Gasto Electoral.

53 Ver en ETCHepare J., Jaime, "¿Es el sistema electoral binominal intrínsecamente perverso?”. En base a estos resultados, difícilmente puede sostenerse la existencia de "graves injusticias". Ya que ambas 


\begin{tabular}{|l|l|c|c|c|}
\hline Año Elecc. & Partido/ Pacto & T\% Votación & T\% Elegidos & Diferencia \\
\hline \multirow{2}{*}{1989} & P. D.C. & 26,4 & 32,5 & $+6,1$ \\
& Concertación & 51,3 & 60,0 & $+8,7$ \\
& R.N. & 19,8 & 26,7 & $+6,9$ \\
& Pacto D. y P. & 33,9 & 40,0 & $+6,1$ \\
\hline \multirow{2}{*}{1993} & P. D.C. & 27,16 & 30,83 & $+3,67$ \\
& Concertación & 55,46 & 57,43 & $+1,97$ \\
& R.N. & 16,25 & 24,16 & $+7,91$ \\
& Pacto U. por P. & 36,51 & 39,52 & $+3,01$ \\
\hline \multirow{2}{*}{1997} & P. D.C. & 22,98 & 31,6 & $+8,68$ \\
& Concertación & 50,46 & 57,43 & $+6,03$ \\
& R.N. & 16,78 & 20,83 & $+4,05$ \\
& Pacto U. Ch. & 36,21 & 39,13 & $+2,92$ \\
\hline \multirow{2}{*}{2001} & P. D.C. & 18,90 & 20,00 & $+1,10$ \\
& Concertación & 47,90 & 52,50 & $+4,60$ \\
& UDI & 25,40 & 29,16 & $+3,76$ \\
& Pacto A.Ch. & 44,30 & 47,49 & $+3,19$ \\
\hline \multirow{2}{*}{2005} & P.D.C. & 19,02 & 17,50 & $-1,52$ \\
& Concertación & 47,41 & 54,16 & $+6,75$ \\
& UDI & 20,48 & 28,33 & $+7,85$ \\
& Pacto A.Ch. & 35,47 & 44,99 & $+9,52$ \\
\hline
\end{tabular}

Completándolo, y señalando siempre porcentajes de votación nacional, corresponde consignar que:

- En 1989 sumados los 8 partidos minoritarios, agrupados en 4 pactos, obtuvieron el $13,8 \%$ en total, sin elegir diputados.

- En 1993 el Partido Comunista obtuvo el 4,98\% de los sufragios y el Partido Humanista-Verde el $1,04 \%$, ambos sin elegir diputados.

- En 1997 el Partido Comunista obtuvo el 6,86\% de los sufragios y el Partido Humanista Verde el 2,91\%, ambos sin elegir diputados; sí ocurrió con el Partido Unión de Centro Centro, que con el 2,14\% de los sufragios eligió dos diputados. ${ }^{54}$

- En 2001 el Partido Comunista obtuvo el 5,20\% de los sufragios, el Partido Humanista el $1,10 \%$ y los candidatos independientes el $1,40 \%$, todos sin elegir diputados; $y$

combinaciones mayoritarias están sobrerrepresentadas. Los perjudicados son los independientes y colectividades que individualmente no alcanzan a obtener un cinco por ciento del total de votos emitidos, cifra que es el monto de la "barrera de entrada" más común en las democracias europeas.

54 Ello se debió a que se concentraron los sufragios en dos distritos electorales. 
- En 2005, el Partido Comunista obtuvo el 4,71\% de los sufragios y el Partido Humanista el 1,43\%, ambos sin elegir diputados; sí ocurrió con el Partido Acción Regionalista, que con el $0,37 \%$ de la votación eligió un diputado. ${ }^{55}$

Al margen de este tema es importante apreciar cuál es la situación del padrón electoral, o sea, del número de personas inscritas, cuyas cifras globales del período son las siguientes:

$$
\begin{aligned}
& 1988 \text { : } 7.435 .913 \text { (55\% de la población) } \\
& 1995 \text { : } 7.963 .954 \text { (59\% de la población) } \\
& 1999: 8.084 .476 \\
& 2001 \text { : 8.075.446 (53\% de la población) } \\
& 2005: 8.220 .897 \\
& 2006: 8.085 .931 \\
& 2007 \text { : } 8.035 .669 \text { (50\% de la población). }
\end{aligned}
$$

Estas cifras, que indican una detención en el crecimiento del padrón electoral, deben considerarse teniendo presente, además, la notable variación que ésta ha experimentado en cuanto a lo ocurrido con la edad de los inscritos, registrándose lo siguiente:

Entre 18 y 29 años : en 1988 el $36,03 \%$ y en 2007 el 7,66\%.

Entre 30 y 54 años : en 1988 el $44,77 \%$ y en 2006 el 58,69\%; y

Entre 55 años y más : en 1988 el 19,20\% y en 2006 el 33,65\%.

Respecto a la abstención ${ }^{56}$ registrada en el período y remitiéndose los datos a plebiscito y elecciones presidenciales, puede consignarse que existe en un creciente aumento de sus niveles. Los porcentajes son los siguientes:

$$
\begin{aligned}
& 1988: 2,47 \% \\
& 1989: 5,30 \% \\
& 1993: 8,68 \% \\
& 2000: 9,37 \% \\
& 2006: 12,33 \%{ }^{57}
\end{aligned}
$$

23) Para la debida utilidad y comprensión de estos datos debe consignarse que el tema de fondo es el de la falta de voluntad en la participación en los procesos electorales.

Porque si se consideran las personas que estando inscritos en los registros electorales se abstienen de sufragar, pero también se agregan los que votan en blanco o nulo

55 La causa de lo cual se encuentra en que se concentraron los sufragios en un distrito electoral.

56 O sea, los electores inscritos que no sufragan en las elecciones.

57 Todas las cifras señaladas en este párrafo corresponden a datos oficiales del Servicio Electoral. Los porcentajes de población son aproximados a los censos correspondientes.

$Y$ en cuanto a otros datos, los porcentajes de abstención tratándose de elecciones parlamentarias y municipales son muy superiores. 
y los que teniendo derecho a hacerlo no se inscriben en los registros electorales todos ellos, estimativamente, hacen subir el número de personas que no participan a aproximadamente un $25 \%$ en las elecciones presidenciales, un $30 \%$ en las parlamentarias y un $33 \%$ en las elecciones municipales.

Lo anterior deriva del hecho muy preciso de existir niveles no menores de indiferencia, cuando no de rechazo, hacia la actividad política, especialmente de parte de los más jóvenes.

Los datos existentes ${ }^{58}$ sobre inscripciones por edad entregan resultados que permiten obtener claras conclusiones. Remitidos a los 20 años recientes, y resumiendo lo esencial se sintetizan seguidamente:

\begin{tabular}{|c|c|c|c|c|c|c|c|}
\hline Año & $\begin{array}{c}\text { Edad } \\
18-19 \\
\text { años }\end{array}$ & $\begin{array}{c}\text { Edad } \\
\text { 30-34 } \\
\text { años }\end{array}$ & $\begin{array}{c}\text { Edad } \\
45-49 \\
\text { años }\end{array}$ & $\begin{array}{c}\text { Edad } \\
55-59 \\
\text { años }\end{array}$ & $\begin{array}{c}\text { Edad } \\
65-69 \\
\text { años }\end{array}$ & $\begin{array}{l}\text { Edad } \\
75-79 \\
\text { años }\end{array}$ & $\begin{array}{l}\text { Total de } \\
\text { Votantes }\end{array}$ \\
\hline 1988 & $\begin{array}{r}409.109 \\
5,5 \%\end{array}$ & $\begin{array}{r}929.8 \\
12,5\end{array}$ & $\begin{array}{r}547.097 \\
7,36 \%\end{array}$ & $\begin{array}{r}426.620 \\
5,74 \%\end{array}$ & $\begin{array}{r}257.729 \\
3,47 \%\end{array}$ & $\begin{array}{r}126.365 \\
1,70 \%\end{array}$ & $\begin{array}{r}7.435 .913 \\
100 \%\end{array}$ \\
\hline 1997 & $\begin{array}{r}85.586 \\
1,07 \%\end{array}$ & $\begin{array}{r}1.173 .152 \\
14,62 \%\end{array}$ & $\begin{array}{r}721.972 \\
8,99 \%\end{array}$ & $\begin{array}{r}511.017 \\
6,37 \%\end{array}$ & $\begin{array}{r}383.216 \\
4,77 \%\end{array}$ & $\begin{array}{r}183.210 \\
2,28 \%\end{array}$ & $\begin{array}{r}8.026 .980 \\
100 \%\end{array}$ \\
\hline 200 & $\begin{array}{r}13.352 \\
0,17 \%\end{array}$ & $\begin{array}{r}630.579 \\
7,85 \%\end{array}$ & $\begin{array}{r}1.069 .003 \\
13,30 \%\end{array}$ & $\begin{array}{r}705.347 \\
8,78 \%\end{array}$ & $\begin{array}{r}464.514 \\
5,78 \%\end{array}$ & $\begin{array}{r}288.730 \\
3,59 \%\end{array}$ & $\begin{array}{r}8.035 .669 \\
100 \%\end{array}$ \\
\hline
\end{tabular}

Como forma de superar esta situación, y sin atender a las causas de origen del problema, se ha insistido, recientemente, en la inscripción automática de los electores, con voto voluntario, así aprobándose en el Senado, en general. "Q uienes rechazaron plantearon sus dudas sobre la confiabilidad del sistema de inscripción automática o bien se manifestaron por el voto obligatorio"..$^{59}$

Como argumentos a favor de la inscripción automática, según se consigna en el proyecto de ley respectiva, se indica que existen pocas facilidades para inscribirse por ser burocrático el sistema respectivo, que esta nueva forma impediría el envejecimiento del padrón electoral y que llevaría a la ampliación del sufragio. En contra de la inscripción automática se ha señalado que el sistema de inscripción vigente es eficien-

\footnotetext{
58 República de Chile. Servicio Electoral. “Inscripciones por grupos etáreos y sexo, en cantidades y porcentajes. 1988-2007". Santiago, 2008. Lo aquí consignado es un breve resumen, en que además se han reunido los electores, varones y mujeres, de cada año y segmento.

59 La votación fue de 25 votos a favor y 9 en contra. Ver en diario "El Mercurio", de 19 de marzo de 2008.
} 
te, de fácil trámite y que lo que mayormente determina la falta de inscripción es la existencia de la obligatoriedad de sufragar que tienen los inscritos. ${ }^{60}$

24) También, durante el período en estudio se ha insistido en la posibilidad de establecer el derecho a sufragio de los chilenos residentes en el extranjero, tal como se ha consagrado en otros estados. Entre los años 1991 y 2006 se han iniciado tres proyectos de modificación de la ley orgánica constitucional sobre votaciones populares y escrutinios, y uno de reforma constitucional, todos presentados por diputados y que, con distinto curso o se han rechazado en el Senado o en la Cámara, se han archivado 0 se encuentran pendientes. ${ }^{61}$

Las razones planteadas a favor de la incorporación de este derecho se refieren a su existencia en varios estados extranjeros, la discriminación que se hace con los chilenos que residen fuera del país, la existencia de comunidad de vínculos con ellos, los aportes que podrían efectuar, el número de personas, ${ }^{62}$ los ofrecimientos electorales y la existencia de recursos que permitirían organizar los procesos electorales en el extranjero.

Contradictoriamente se ha señalado que no es procedente otorgar este derecho porque no sería un preocupación política y electoral de importancia; no concitaría apoyo mayoritario, e incluso han fracasado acuerdos políticos previos, por afectar el derecho a la igualdad a la ley ya que sólo podrían ejercer el derecho en las elecciones presidenciales; la imposibilidad de mantener el orden público como en Chile; las dificultades en el ejercicio de la justicia electoral; las discriminaciones en la aplicación de las normas del sistema electoral público; la existencia de otros vínculos con los países en que residen las personas involucradas; el no compartir quienes viven en el exterior las mismas cargas que recaen sobre los chilenos que viven en el territorio nacional, y la posibilidad de acentuarse, en el extranjero, la intervención electoral de los años recientes.

Las iniciativas no han prosperado, principalmente por las objeciones de constitucionalidad y, en lo concreto, por las críticas hacia los riesgos de la intervención electoral gubernativa. A un cuando no existe certeza respecto de la preferencia que pueden

60 Ver en INFANTE D., Carolina, “Proyecto de ley que establece la inscripción automática y el voto voluntario", impreso, 7 de julio de 2008, pp. 1 a 11.

61 Previo un proyecto de reforma constitucional, presentado por el gobierno del Presidente Salvador Allende G., de 16 de enero de 1971, en los últimos casi 20 años se han iniciado los siguientes: a) Proyecto de ley de 15 de enero de 1991, por moción de los diputados Carlos Dupré, Sergio Elgueta, Hernán Bosselin y Hernán Rojo, rechazado en la Comisión respectiva del Senado; b) Proyecto de ley de 15 de junio de 1993, por moción del diputado Mario Palestro, archivado; c) Proyecto de ley de 20 de julio de 2005, por moción de los diputados Isabel Allende, Sergio Aguiló, Juan Bustos, Francisco Encina, Carlos Montes y Fulvio Rossi, rechazada por la sala de la Cámara de Diputados; y d) Proyecto de reforma constitucional de 5 de octubre de 2006, por moción de los diputados Maximiano Errázuriz, Germán Becker, Francisco Chahuán, Roberto Delmastro, René García, Joaquín Godoy y Roberto Sepúlveda, pendiente en su tramitación.

62 Según cifras oficiales, publicadas por el Ministerio de Relaciones Exteriores de Chile en el año 2005, 857.781 chilenos, eventualmente votantes, residen en el extranjero, con un $61 \%$ en Sudamérica, el $18,3 \%$ en Norteamérica, el $16,6 \%$ en Europa y el $4,1 \%$ en otros continentes. 
tener estos eventuales electores, la especial insistencia de los gobiernos en cuanto al otorgamiento del derecho, sumada a los estrechos resultados de las más recientes dos elecciones presidenciales, han motivado la politización del tema y su falta de aprobación en el Congreso.

25) El tema no menor de la "intervención electoral" se ha agregado en los años más cercanos, estimándosele como un factor negativo para el desarrollo democrático. Singularizándola principalmente en las visitas de autoridades y funcionarios a terreno, uso de recursos fiscales en ello, publicidad fiscal, aumento del gasto público y de las urgencias legislativas en los períodos electorales y actividad de los denominados "operadores políticos", con financiamiento público. ${ }^{63}$

Quienes han criticado estos procedimientos han formulado proposiciones consistentes en fortalecer la transparencia y control de los gastos electorales y de la propaganda, dictar una ley anticorrupción y tipificar como delito funcionario cualquier acto de intervencionismo electoral, ${ }^{64}$ agregándose la sanción al abuso de cargos públicos de alta exhibición mediática y la dictación de un Estatuto de Garantías Electorales, similar al existente en estad os como Inglaterra, Estad os Unidos, España, Francia, Alemania y Colombia. ${ }^{65}$

M uy recientemente, y pese a las iniciativas legislativas en tal sentido, el tema ha recrudecido, expresándose criterios muy opuestos, como el indicado por un alto funcionario de gobierno, que se estima justifica la intervención electoral, y el indicado por representantes de la oposición en cuanto la rechazan. ${ }^{66}$

26) Pertinentemente al tema tratado en este párrafo, atendido que vincula a los partidos políticos con el sistema electoral, se ha dado a conocer en Chile, recientemente, un estudio nacional de especial interés. ${ }^{67}$

A partir de consultas nacionales sobre el apoyo a la democracia y confianza en las instituciones, se obtuvieron los siguientes principales resultados.

63 Ello motivó, entre otras reacciones, la formación, en abril de 2006, de una Comisión Investigadora de la Cámara de Diputados, que emitió su informe en noviembre del mismo año, aprobado por mayoría.

64 Ver en Cámara de Diputados, Comisión Investigadora referida, A nexos.

65 Garcia G., José Francisco y Brunet B., Marcelo (2007). “Aumentando los estándares democráticos del proceso político chileno: reformas pendientes en materia de fiscalización política, intervención electoral del gobierno y garantías electorales", en Universidad de Chile, Facultad de Derecho, Revista de Derecho Público, Volumen 69, Tomo I, pp. 216-232.

66 El subsecretario de Previsión Social "justifica la intromisión del Gobierno en proceso electoral. La legitimidad de mostrar lo que ha hecho, de disputar la voluntad de los electores, es parte del juego democrático, dice". Por su parte, directivos opositores señalaron que "El intervencionismo electoral... está nítido y claro en la clase o discurso que dio el subsecretario, donde dice con claridad que aquí todo es para ganar votos". Relación en diario "El Mercurio", Santiago, de 30 de agosto de 2008.

67 Efectuado por la Corporación de Estudios para Latinoamérica (Cieplan), Libertad y Desarrollo, Proyecta Corporación y el Centro de Estudios Públicos, "Estudio Nacional sobre Partidos Políticos y Sistema Electoral. marzo-abril 2008". Corresponde a una recolección de datos entre el 26 de marzo y el 16 de abril de 2008, con cobertura nacional y error muestral estimado en $+3 \%$ y $95 \%$ de confianza. 
a) La estimación por un $45 \%$ de que la democracia es preferible a cualquier otro sistema. En tanto que a un $29 \%$ le da lo mismo que exista un sistema autoritario y a un $18 \%$ le parece que en algunas circunstancias el gobierno autoritario puede ser preferible a uno democrático.

b) En cuanto al funcionamiento de la democracia en Chile, un $57 \%$ lo estima regular; un $24 \%$ mal o muy mal y un $15 \%$ lo estima bien.

c) Respecto de las instituciones que aparecen con mayor confianza, se encuentran Carabineros, con 57\%; Fuerzas Armadas, con 51\%; Iglesia Católica y las Radios, con 48\%; la Televisión, con 34; las M unicipalidades, con 31\% y el Gobierno y las Iglesias Evangélicas, con el 30\%. Las instituciones con menor grado de confianza serían las Empresas Estatales, con 21\%; las Empresas Privadas y los Tribunales de Justicia, con $18 \%$; el Congreso, con $16 \%$ y los Partidos Políticos, con $6 \%$.

d) En cuanto a las combinaciones políticas chilenas actuales, el $14 \%$ tiene confianza en la Concertación de Partidos por la Democracia; el $12 \%$ en la Alianza por Chile y el $6 \%$ en el pacto Juntos Podemos.

e) Respecto de niveles de corrupción en servicios públicos, el $94 \%$ señala que no ha tenido experiencias de ese orden y un $6 \%$ que sí.

Y en cuanto a la confianza en temas vinculados a sistema electoral y partidos políticos, a partir de las correspondientes consultas, se obtuvieron los siguientes principales resultados:

a) Un $28 \%$ declara no estar inscritos en los registros electorales. No lo están el $77 \%$ de las personas entre 18 y 24 años de edad y el $52 \%$ entre quienes tienen 25 y 34 años. Dándose como razones principales la falta de interés, el $59 \%$, y el hecho que los políticos no abordan los problemas que interesan, el $41 \%$.

b) Un $78 \%$ señala que el voto debería ser voluntario y un $21 \%$ que debe ser obligatorio, siendo casi iguales las opiniones en cuanto a la inscripción automática, el 52\% que no y el $47 \%$ que sí. El $63 \%$ estima que como vota puede influir en lo que pasa en el país.

c) Tampoco existen diferencias sustanciales en cuanto al cambio del sistema electoral. Un 25\% prefiere mantener el sistema binominal; el 24\% mantenerlo con modificaciones; el $25 \%$ cambiarlo totalmente y el $26 \%$ no sabe o no contesta.

d) El $71 \%$ opina que existan pocos y grandes partidos políticos o bloques y el $16 \%$ que existan muchos, con un $13 \%$ que no sabe o no contesta.

e) Se aprecia un escaso porcentaje de personas, el 3\%, que señala pertenecer a un partido político. El 21\% reconoce pertenecer a Iglesia u otra organización religiosa; el 
$14 \%$ a un grupo deportivo; el $9 \%$ a una fundación o grupo de beneficencia y, entre otros, el $7 \%$ a un grupo cultural y el $6 \%$ a un sindicato.

f) El $62 \%$ se declara nada interesado en la política; algo interesado un $26 \%$, bastante interesado el $7 \%$ y muy interesado el $4 \%$.

g) En una evaluación general de los partidos políticos ésta fluctúa entre 2,84 (Comunista) y 3,80 (Renovación Nacional). Un 94\% no haría aportes a algún partido político.

h) El $82 \%$ es de opinión de que el Estado no debería hacer aportes a los partidos políticos fuera de campaña y un $13 \%$ estima que sí.

i) Respecto de la forma de elegir candidatos, el $53 \%$ es de opinión que deberían serlo en primarias o elecciones abiertas, el $22 \%$ en también por medio de tales procedimientos pero en que sólo participen los militantes y un $8 \%$ prefiere se designen por los máximos dirigentes de los partidos.

j) El $48 \%$ opina que los parlamentarios deben votar según sus propias preferencias y el $32 \%$ de acuerdo a lo que prefiere el partido a que pertenecen.

\section{CONCLUSIONES GENERALES}

Sin perjuicio de todo lo directamente analizado precedentemente, es pertinente resumir algunas conclusiones generales:

A) Para la debida comprensión de la evolución del régimen político chileno es necesario tener presente los antecedentes propios de nuestra tradición social y político constitucional.

B) En el período de los recientes 30 años se dictó y entró en vigencia la Constitución Política de la República de 1980. Cuyo texto y aplicación han experimentado, en los cercanos 20 años importantes modificaciones.

C) Durante el período se han preservado sin cambios principalmente las bases de la institucionalidad, los derechos fundamentales y su protección, el sistema político presidencial, el sistema electoral y la autonomía del Banco Central.

D) No obstante lo anterior, el sistema presidencial, también por la reducción a 4 años del período del gobernante así como por los hechos sociales y políticos del período, no tiene el mismo peso y significado original. El Presidente de la República, de manera parecida a la del período de vigencia de la Constitución Política de 1925 sólo que con otras modalidades, ha debido gobernar -también en materias propias de su cargo- en necesario acuerdo con los partidos políticos representados en el Congre- 
so, lo que es una de las razones de la inestabilidad ministerial que está caracterizando a los años recientes.

El rol de algunos ministros tampoco parece ser el propio de las formas presidenciales.

E) En muchas otras materias los cambios se han dirigido hacia sustituir o variar algunas de las finalidades propias de la elaboración de la Constitución Política, con acento en el término del pluralismo ideológico limitado, la composición mixta o no electiva del Senado, la eliminación de la intervención militar en la sociedad política, la modificación de los elementos de rigidez del procedimiento de reforma constitucional. Y, además, recuperándose las funciones políticas, reafirmando el rol de los partidos políticos y del Congreso Nacional.

Como también hacia incorporar modificaciones en la generación del Poder Judicial e, importantemente, en cuanto a robustecer la justicia constitucional.

F) Tales cambios, reflejados también en muchos textos legislativos y decisiones públicas, han sido producto de modificaciones en las realidades políticas, de la falta de tradición de algunas de las normas originales de la Constitución, del predominio electoral de la combinación política mayoritaria y de los acuerdos políticos producidos.

G) En materia electoral se aprecia una plena regularidad y en tal forma se han cumplido todas las etapas y procesos correspondientes. No obstante, se observan precisas y crecientes señales de aumento de algunos elementos de malestar o indiferencia pública. Entre éstos se pueden mencionar la detención en el incremento del pad rón electoral y la negativa de los segmentos más jóvenes en cuanto a inscribirse en los registros electorales. Para la atención de este problema no se ha ido al fondo de la cuestión sino que parecen buscarse soluciones puramente formales. Asimismo, en el siempre difícil camino que históricamente se recorre hacia la libertad electoral, el renacer de una intervención electoral puede aparecer como un riesgo que debería evitarse a favor del ejercicio de la indicada libertad.

H) El sistema electoral binominal en las elecciones parlamentarias ha cumplido con sus finalidades de estabilidad y de evitar la dispersión política, pero subsiste su crítica fundada a la falta de representación de los partidos políticos minoritarios y de los independientes.

I) Debe también concluirse que un extenso y ya abandonado debate sostenido en Chile en cuanto a en qué oportunidad se habría puesto término a "la transición" ha cedido a la realidad y al conocimiento histórico, que demuestran no depender ello, en cualquier época, de determinaciones voluntarias.

Sino que, en verdad, los procesos evolutivos van siempre incorporando y mezclando a través del tiempo diversas experiencias, lo que hace que nada puede separarse en forma tan tajante.

El régimen político chileno y su evolución son un caso más de suma de experiencias. 


\section{BIBLIOGRA FÍA}

Actas de la Comisión de Estudio de la Nueva Constitución de la República. Santiago, Chile, 1973-1978.

A ctas del Consejo de Estado, Proyecto Constitución Política, Informe, Santiago, Chile, 1978-1980.

Actas XXXIV Jornadas de Derecho Público, Facultad de Derecho, Pontificia Universidad Católica de Chile, Santiago, Chile, 2005.

Blanc R., Neville; Nogueira A., Humberto; Pfeffer U., Emilio; Verdugo M., Mario (1990). "La Constitución Chilena", Centro de Estudios y Asistencia Legislativa, Universidad Católica de Valparaíso, Valparaíso, Chile.

Bravo L., Bernardino (1996). El Estado de Derecho en la Historia de Chile, Ediciones Universidad Católica de Chile, Santiago, Chile, y (1998), “El Presidente en la Historia de Chile", Santiago, Chile.

Carrasco D., Sergio (2002). "Génesis y Vigencia de los Textos Constitucionales Chilenos", 3a edición, Santiago, Chile,

Carrasco D., Sergio (1995). “Estudio histórico del período de vigencia de la Constitución Política de 1925", Proyecto Fondecyt-Conicyt n 1930466, Concepción, Chile.

Carrasco D., Sergio (2004). "Estudio histórico jurídico sobre la génesis, aplicación y reforma de la Constitución Política de 1980", Proyecto Fondecyt-Conicyt, n 1010906, Concepción, Chile.

Consejo General del Colegio de A bogados de Chile (1980). Antecedentes histórico-jurídicos, años 1972-1973, Santiago, Chile.

GuerRa, José Guillermo (1925). La Constitución de 1925, Santiago,

Revista Chilena de Derecho, Facultad de Derecho, Pontificia Universidad Católica de Chile, Número especial, Santiago, Chile,1998.

Revista de Derecho de la Universidad Católica de la Santísima Concepción, N 8, Concepción, Chile, 2000.

Revista de Derecho de la Universidad de Concepción, Facultad de Ciencias Jurídicas y Sociales, N²12, Concepción, Chile, 2003.

Revista de Derecho Público, Universidad de Chile, Facultad de Derecho, Departamento de Derecho Público, Volumen 69, Santiago, 2007.

Revista Estudios Constitucionales, Centro de Estudios Constitucionales de Chile, Universidad de Talca, Facultad de Ciencias Jurídicas y Sociales, Año 1, n 1, Santiago, Chile, 2003.

Revista Derecho Mayor, Escuela de Derecho Universidad Mayor, $n^{\circ} 1$, Temuco, Chile, 2002.

Servicio Electoral República de Chile. Datos y Cuadros Resúmenes. Santiago, 2007.

VV.AA. en Editores: Fontaine, Arturo; Larroulet, Cristián; Viera-Gallo, José Antonio y W ALKER, Ignacio (2007). Modernización del Régimen Electoral Chileno, Cieplan, Libertad y Desarrollo, CEP y Proyecta A mérica, Santiago, Chile.

VV.AA. en Editores: Fontaine, Arturo; Larroulet, Cristián; Viera-Gallo, José Antonio y W ALKer, Ignacio (2008). Estudio Nacional sobre Partidos Políticos y Sistema Electoral. Marzo-A bril 2008, Santiago, Chile,

VV.AA., ZúñIga U., Francisco (Coord.) (2005). Reforma Constitucional, Santiago, Chile. XXXV Jornadas Chilenas de Derecho Público, Universidad de Valparaíso, Facultad de Derecho, Valparaíso, Chile, 2006. 